\title{
DIVERTIMENTOS, ESPORTES E A MODERNIDADE RELATIVA NA CIDADE DE BELO HORIZONTE: ANOS 1930 E $1940^{1}$
}

Recebido em: 06/01/2017

Aceito em: 28/08/2017

\author{
Sarah Teixeira Soutto Mayor ${ }^{2}$ \\ Sílvio Ricardo da Silva ${ }^{3}$ \\ Universidade Federal de Minas Gerais (UFMG) \\ Belo horizonte $-\mathrm{MG}-$ Brasil
}

RESUMO: Este estudo tem como objetivo analisar e problematizar reportagens produzidas em periódicos da cidade de Belo Horizonte, Minas Gerais, nos anos 1930 e 1940, centrando-se, especificamente, em veiculações que relacionaram formas de divertimento e de esportes, em geral, a uma possibilidade privilegiada de alcance do progresso. Cinema; teatro; casas de baile e de jogos; e manifestações esportivas foram citados em meio a indicativos quantitativos que explicitavam o crescimento da cidade, servindo como um dos suportes argumentativos na veiculação de uma localidade que urgia pela visibilidade de outros centros urbanos e pela denominação de "moderna", ainda que relativa e intangível.

PALAVRAS CHAVE: Jogos e Brinquedos. Esportes. Atividades de Lazer.

\section{ENTERTAINMENT, SPORT AND RELATIVE MODERNITY IN THE CITY OF BELO HORIZONTE: 1930S AND 1940S}

ABSTRACT: This study aims to analyze and discuss reports produced in print media newspapers and magazines - of the city of Belo Horizonte, Minas Gerais, between 1930 s and 1940s, focusing specifically on topics related to the forms of entertainment and sports as a privileged possibility of reaching the progress. Cinema,; theatre; House of Ball and sports events were, in general, cited as quantitative indicatives that spelled out the city's growth. In addition, such indications served as an argumentative support in the placement of a locality that sought a visibility vis-à-vis other urban centers and a domination as "modern", although relative and intangible.

\footnotetext{
${ }^{1}$ Esta pesquisa foi realizada com financiamento da CAPES.

2 Doutora em Estudos do Lazer pela UFMG. Membro do GEFuT: Grupo de Estudos sobre Futebol e Torcidas (UFMG); Membro do Oricolé: Laboratório de Pesquisa sobre Formação e Atuação Profissional em Lazer (UFMG).

${ }^{3}$ Docente do Programa de Pós-Graduação em Estudos do Lazer da UFMG. Líder do GEFuT: Grupo de Estudos sobre Futebol e Torcidas - UFMG.
} 
KEYWORDS: Play and Playthings. Sports. Leisure Activities.

\section{Introdução}

O presente artigo tem como objetivo problematizar a utilização discursiva dos divertimentos e dos esportes, em suas variadas facetas, como um dos contributos para a afirmação do progresso e da modernidade de Belo Horizonte, capital do estado de Minas Gerais. Aliada a outros referenciais, tais como, número de edificações construídas, extensão de área asfaltada, implantação e expansão de serviços de saúde, educação e saneamento, incremento das atividades comerciais, dentre outras intervenções no cenário social, os esportes, juntamente com algumas manifestações de diversão - a exemplo do cinema, do teatro e da dança - lograra importante visibilidade dentre as características veiculadas sobre a cidade em alguns periódicos durante os anos 1930 e 1940, tornando-se indicativo da tentativa de consolidação da jovem capital construída no final do século XIX.

Em se tratando da prática esportiva, o olhar da imprensa sugeria uma possibilidade fértil não apenas para se propagandear o progresso citadino, mas também, para difundir valores educativos considerados essenciais para a formação do novo cidadão belo-horizontino. Torna-se importante salientar que os esportes estão mencionados como algo a parte dos divertimentos porque assim era comumente veiculados, o que certamente não implica desconsiderar que as práticas esportivas também podem se constituir em possibilidade de diversão.

As assertivas supracitadas tornaram-se possíveis de serem formuladas e problematizadas por meio da leitura e análise de jornais e revistas que circularam na 
cidade no período proposto, a saber: revista Alterosa, revista Bello Horizonte ${ }^{4}$, revista Minas Tenis, revista Leitura e jornal Estado de Minas. Embora distintos em vários quesitos, o que envolve comissão editorial, tipo de público consumidor, tiragem, periodicidade e tempo de circulação no mercado jornalístico, todas estas publicações possuíam um ponto convergente: a veiculação expressiva dos feitos realizados na cidade de Belo Horizonte, sobretudo, a ação de políticos em momentos comemorativos, como no aniversário do município, que se cumpre no dia 12 de dezembro.

Para fins deste artigo, não serão aprofundadas as características de cada periódico, o que demandaria um texto próprio apenas para tratar desse assunto, haja vista que a análise se baseia em cinco títulos. No entanto, torna-se importante dizer que as revistas, em especial, eram comercializadas para um público mais restrito, em se tratando do poderio econômico e social. Suas páginas eram recheadas de fotografias do que se chamava à época de "distinta sociedade" ou "escol social” e seus conteúdos eram majoritariamente direcionados para preocupações relacionadas ao modo de vida das parcelas mais abastadas da cidade. Dentre as que mais fortemente detinham esta característica, pode-se destacar a Minas Tenis, veículo criado pela entidade homônima, um clube social e esportivo fundado em 1935. O Minas Tênis Clube era considerado, no período, o principal empreendimento esportivo do estado ${ }^{5}$. As diversões e os esportes, no contexto de seu impresso, eram enfaticamente difundidos como atividades formativas para um grupo distinto: os associados do Minas Tênis Clube e de outros clubes privados.

Já o jornal, aqui representado pelo Estado de Minas, possuía maior alcance de público e suas reportagens se diferenciavam das revistas por conter maiores detalhes

\footnotetext{
${ }_{5}^{4} \mathrm{Na}$ década de 1940, a revista alterou sua grafia para "Belo Horizonte".

5 Para maiores informações, ver a dissertação de autoria de Marilita Aparecida Arantes Rodrigues:

"Constituição do sentido moderno de esporte: pelas trilhas históricas do Minas Tênis Clube" (1996).
} 
sobre o cotidiano do país e da cidade, explicitados de maneira mais acessível. Embora tenha sido (e ainda seja) um veículo capitaneado por empresários que desfrutam de alto poder econômico, pode-se dizer que sua produção se direcionava para qualquer público leitor, haja vista a simplicidade de sua linguagem, a grande quantidade de seções, o material barato de sua confecção (diferente das revistas), a periodicidade diária de sua produção e a vastidão de assuntos que abordava, incluindo problemas simples do cotidiano citadino da região central e da periferia.

Tendo em vista essas considerações preliminares, foram selecionadas reportagens de todos os periódicos sinalizados e, em momento posterior, analisada e problematizada a forma como algumas das diversões e dos esportes que se faziam presentes na cidade era veiculada, atentando-se especificamente, à maneira como estas manifestações eram relacionadas aos indicativos de progresso e de modernidade.

\section{Reverberações acerca da Construção da Cidade-Capital}

A capital fez annos este mez:

O Abilio sabe ao certo quantos fez.

Bello Horizonte é moço, vem surgindo, Mas nem por isso deixa de ser lindo. Ha muita ‘joven' por ahi, bem sei, Que ainda é do tempo de Curral d'EL Rey... Do tempo em que Aarão Reis sobre a poeira Traça a planta da cidade inteira. [...] E o tempo foi rondando, foi passando, Bello Horizonte foi se transformando... Veio o 'Benz', veio após o 'Chevrolet' $\mathrm{E}$ a capital tornou-se isso que é... Casas de typo A, de Typo B, São muito raras, quasi ninguém vê... [...] Hoje Bello Horizonte é differente, Tem outros modos e tem outra gente... Tem cinemas de luxo e tem cafés, Ha clubs de alta roda e cabarets. Ha mais chic, a elegancia é bem maior, As meninas imitam Joan Crawford!... Ah! Nenhuma quer ser, eu bem sei, A moça simples de Curral d'EL Rey (DOM RUY, 1936, p.13). 
Arquitetada para emergir como uma urbe moderna, Belo Horizonte se ergueu nas terras de um antigo povoado chamado Curral D'EL Rey e, desde os primeiros momentos de sua idealização, nota-se a explícita intenção de se criar uma cidade-capital condizente com as novas orientações republicanas. Nas palavras de Julião (1996, p.49), "Belo Horizonte figura como obra simbólica de maior envergadura da República em Minas".

Em seus registros, o memorialista Abílio Barreto (1941, p.78) relata que após a proclamação do novo regime governamental em 1889, o "Clube Republicano", então fundado em Curral d'El Rey, deliberou tirar da localidade "os últimos ranços da monarquia e obteve daquele governador provisório a mudança do nome pelo qual era conhecido havia quasi dois séculos". Com essa medida, Curral D’El Rey passou a chamar-se Belo Horizonte, "nome que manteve durante sete anos, pois inaugurada a nova Capital, esta recebeu a denominação de "Minas" e a reteve até 1901, quando uma lei do Congresso Mineiro restabeleceu a denominação de 'Belo Horizonte' para a nova cidade" (IDEM).

A necessidade de dotar Minas Gerais de um centro administrativo compreendido e visto como moderno, de acordo com as tendências vislumbradas em outras metrópoles mais antigas e consolidadas, era premente. Para Carvalho $(2005$, p.64) a simbologia da modernidade conferida à capital refletia-se nas "linhas geométricas de seu traçado urbano, em forma de tabuleiro de xadrez, no cartesianismo de sua concepção, à maneira do Barão de Haussmann, reformador de Paris, e de L' Enfant, planejador de Washington, e na designação de áreas específicas para indústrias”.

Além destas influências, outras experiências citadinas se fizeram presentes no delineamento do plano arquitetônico de Belo Horizonte, como é o caso da cidade 
argentina de La Plata. Uma carta escrita no ano de 1894 pelo engenheiro-chefe da C.C.N.C, Aarão Reis, endereçada a um brasileiro residente na Argentina, Dr. Fernando Osório, demonstrava o interesse de Reis no intercâmbio de informações que pudesse lhe auxiliar na consecução da nova capital:

[...] Acho-me encarregado, pelo Governo do Estado de Minas Gerais, da direcção technica e administrativa da Comissão Construtora da Nova Capital e, no intuito de dar a semelhante trabalho a máxima perfeição, desejo colligir tudo quanto, no estrangeiro, possa guiar-me bem. E por isso, tomo a liberdade de solicitar de V Exc., que se acha colocado na Republica Argentina nas melhores condições, o especial obsequio de obter e remetter-me quaesquer dados relativos ás grandes cidades dessa República, que me possam ser uteis, taes como: plantas, vistas, memorias, dados estatísticos, descripções technicas, regras e posturas municipaes, legislação e regulamentação policial, disposições sanitárias e hygienicas, etc. É minha tenção aproveitar a primeira folga, que me permittam os meus arduos encargos aqui, para dar um pulo até ahi e examinar 'de visu' as grandes e bellas cidades modernas do Prata, e para essa projetada excursão, já convidei até o Dr. Afonso Penna $^{6}$, para irmos juntos [...] (DUAS, 1940, p.11).

Arruda (2012), ao realizar um estudo histórico comparativo entre a construção das cidades de Belo Horizonte e de La Plata, relata que a segunda serviu ao engenheiro Aarão Reis como uma das referências no planejamento e na edificação da nova capital mineira, junto a outras metrópoles já mencionadas, como Washington e Paris, acrescentando-se Londres. De acordo com o autor, La Plata se destacava aos olhos dos mineiros pelo seu desenho, pela regularidade, pela linearidade e pela busca da harmonia dos espaços. Esta cidade, segundo Arruda (2012, p.100), foi "planejada seguindo os padrões da urbanística moderna, que prescreviam a beleza e a salubridade dos espaços como elementos fundamentais para o bem-estar nas populações”. O traçado de Belo Horizonte, em especial o modelo tabuleiro de xadrez, "concebido como uma constante

\footnotetext{
${ }^{6}$ O Dr. Afonso Penna, referido por Araão Reis, era membro do Partido Republicano Mineiro e ocupou o cargo de presidente de Minas Gerais entre os anos de 1892 e 1894. Anos mais tarde, em 1906, foi eleito presidente da república. Uma das principais avenidas de Belo Horizonte possui seu nome.
} 
urbanística histórica" (ARRUDA, 2012, p.102) também pode ser considerada uma das influências da cidade argentina.

Ainda sobre o projeto de criação da nova capital mineira, Julião (1996, p.64) ressalta que a cidade, na visão de seus idealizadores, aparecia como "signo de um novo tempo; centro de desenvolvimento intelectual e de novas formas de riqueza e trabalho". Estas visões também eram frequentemente veiculadas nos periódicos pesquisados. Imagens de Belo Horizonte como "foco irradiador da civilização e do progresso", como "lugar higiênico e elegante, capaz de consolidar um poder vigoroso e assegurar a unidade política do Estado" (DUAS, 1940, p.11) refletiam a produção de uma história heroica, centrada na ação progressista de transformação de um arraial primitivo e colonial em uma metrópole republicana civilizada.

Comparações eram realizadas entre a nova cidade criada e a capital anterior, Ouro Preto. O jornal Diário da Tarde publicou uma reportagem no ano de 1910 em comemoração aos treze anos de Belo Horizonte, intitulada "A cidade moderna". Nela, essa relação foi assim apresentada:

[...] ao contrario das suas irmãs, surgiu já prompta dessas metamorphoses só explicaveis na Fabula [...]. Cidade moderna, toda agitada por uma febre de trabalho, ella se alardea soberba e garrida, como uma noiva, entre as suas velhas e legendárias irmãs, com elas formando um contraste violento e ao mesmo tempo commovedor [...]. A vetusta e ancestral Ouro Preto não olhava, é certo, até ha bem pouco tempo, pelo menos, com muito bons olhos, a jovem e garbosa irmã que lhe usurpou os foros de capital: não lhe agradavam de certo, as aprasiveis avenidas largas e banhadas de sol e luz, margeadas de palacetes, da nova urbe, tão em contraste com suas viellas estreitas e coloniaes, onde velhos e inestheticos pardieiros põem a mancha merencoria e escura da civilisação já morta. [...] Bello Horizonte, com todo o espírito moderno e yankee que a anima, é o presente e o futuro com todas as suas risonhas e promissoras esperanças $(\mathrm{O}$ ANNIVERSARIO..., 1910, p.3).

No trecho supracitado, percebe-se a incapacidade de Ouro Preto, velha cidade colonial, representante do tempo escravagista e do já obsoleto ciclo do ouro, de se 
manter como a capital de um estado que necessitava se adequar aos novos ordenamentos republicanos e se inserir no "espírito moderno" que se alastrava no território brasileiro no final do século XIX. A abolição da escravidão, a proclamação da república e outras mudanças econômicas e sociais, como a migração em massa, o aumento populacional do contingente urbano, o incremento comercial e o investimento na construção de indústrias, alteraram sobremaneira o cenário de grandes capitais do país, a exemplo de Rio de Janeiro, São Paulo, Manaus, Belém e Salvador. Esses fenômenos podem ser considerados desdobramentos do que Sevcenko (1994) denominou de Revolução Científico-Tecnológica ${ }^{7}$. Assim, Belo Horizonte foi criada diante de circunstâncias que já se faziam presentes em outras localidades; situações que, possivelmente, serviram-lhe de referência. Modernidade, febre, agito e trabalho foram as características elencadas para descrever o desenvolvimento desejável da "nova urbe" mineira. Nota-se, ainda, a utilização do termo "yankee", referente aos Estados Unidos, como uma das qualidades do que se entendia como moderno.

\footnotetext{
${ }^{7}$ Para Sevcenko (1993, pp. 81, 82) a Revolução Científico-Tecnológica, também denominada de Segunda Revolução Industrial, abarca um processo de mudanças intensas experimentadas especialmente a partir da década de 1870. Esse processo, segundo a autor, resultou "numa imensa escalada do investimento capitalista, que cresceu em volume e amplitude, permitindo a formação dos modernos complexos industriais baseados na administração científica e na linha de montagem. Esse princípio de produção em massa se expandiu até assumir proporções globais, alcançando, em sua ânsia por matérias primas e por novos mercados, as mais remotas regiões do mundo, até então intocadas pelo investimento capitalista. Como consequência, ocorreram movimentos de migração em massa numa escala jamais vista antes na história. Forçadas pela superexploração e pela pobreza extrema dela decorrente, essas massas encaminharam-se para as novas fronteiras da expansão capitalista, como plantações, zonas de mineração ou áreas industriais concentradas e de crescimento rápido, e aí se estabeleceram aos milhões, dando origem às megalópoles do século XX". Sevcenko cita como exemplo a cidade de São Paulo, "em si mesma um subproduto das lavouras de café", como exemplo "assombroso dessas megalópoles que se multiplicaram rápida e inesperadamente, como cogumelos após a chuva". Diante desse contexto, o autor não se exime de mencionar as mazelas e o caos desse processo de "inchação" urbana, que submeteu a população a "opressões e privações inimagináveis" (p.87). Este fato pode ser pensado em outras realidades brasileiras, incluindo Belo Horizonte em um momento posterior, por meio de suas políticas progressistas de crescimento urbano.
} 
Nas palavras de Abílio Barreto (1940-1941, pp. 19-22) também podem ser vislumbrados alguns dos argumentos mobilizados para a construção da cidade, que sinalizavam as necessidades de ruptura com um modelo urbano ultrapassado.

[...] Mas, desde os tempos coloniais, compreenderam os mineiros, em sua maioria, que aquela venerável e tradicional cidade, nascida ao acaso, em região alpina, inadequada para o desenvolvimento de uma grande metrópole á altura de um povo cônscio de seus destinos altanados no concerto da nacionalidade - teria de perder, algum dia, os seus fóros de Capital, cedendo lugar a outra, que realizasse o belo sonho, a justa aspiração da gente montanhêsa.

Havia um tom de deslumbramento na descrição da nova cidade, que Barreto resumiu como "incontestavelmente, a maior gloria e o mais legítimo orgulho da gente montanhesa" (IDEM). O memorialista enumerou em alguns textos as denominações que atestava ter recebido Belo Horizonte de personalidades reconhecidas à época: "a 'cidade Vergel', como a classificou Coelho Neto, o 'Miradouro do Céu', como a definiu Paulo Barreto, a 'Cidade Certa', como a julgou Monteiro Lobato [...]” (IBIDEM). Barreto ainda complementou seus escritos com a seguinte informação: "Monteiro Lobato, visitando-a outro dia, sentiu-se maravilhado e só encontrou a ela comparável em beleza e sistematização de traçado, a grande Washington, capital dos Estados Unidos (IBIDEM).

Publicações semelhantes se fizeram presentes em vários impressos consultados, especialmente nas reportagens destinadas a comemorações do aniversário da cidade. Pode-se destacar a revista Bello Horizonte, que dedicou em vários de seus números, textos referentes à história de construção da capital, enaltecendo o espírito guerreiro do povo mineiro. Em um registro datado de 1936, intitulado "Cidade das montanhas", é possível perceber algo que seria corrente nos textos da imprensa pesquisada: a 
comparação de Belo Horizonte com outras cidades, seja para enaltecer as suas especificidades, seja para criticar os seus problemas ou as suas insuficiências.

[...] As cidades, na quasi absoluta totalidade, nascem e crescem por vários fatores: por servirem de pouso aos viajadores, por exploração extrativa ou industrial, por necessidade ou contingencias outras que se vão acumulando gotta a gotta, assim nascem e crescem. Tu, não foste ideada, construída e desenvolvida por determinação: as outras foram por força das circunstancias - Tu, pelo desejo firme de um pugillo de antecipadores do futuro [...] Cidade das montanhas! Substituiste um pobre burgo - Trazes a seiva da boa e fecunda terra montanhesa. - Por isso es, hoje, já uma grande metrópole operosa, com cento e setenta mil almas [...] (CIDADE..., 1936, p.39).

Em outras reportagens da mesma revista apelos discursivos análogos podem ser

localizados.

[...] Os mineiros demoliram um pequeno arraial e construíram no seu lugar uma cidade, partindo desde a terraplenagem. Hoje ela é uma das maiores do Brasil, a mais bella talvez, culta e próspera (BELLO HORIZONTE, 1940, p.21).

Em 1897, os mineiros tinham acabado de destruir um arraial, e em seu logar inaugurado uma cidade, destinada a ser metrópole da gente montanhesa. Dahi até hoje são apenas quarenta e tres annos [...] Hoje, bem mais de duzentos e vinte mil habitantes [...] (BELLO HORIZONTE, 1940, p.20-21).

[...] No local do velho casario do arraial de Curral d'El Rey construiuse uma moderna cidade cujo progresso tem sido acelerado e contínuo, sendo hoje, uma das maiores cidades do Brasil, pelo progresso material e por ser também um magnifico centro cultural (COMEMOROU..., 1945, p.87).

[...] no local de uma velha e pequena povoação, ergueu uma rica, grande, culta, progressista e bela cidade, onde mourejam trezentas mil pessoas. Uma das maiores e mais esplendorosas cidades do país [...] (A METROPOLE..., 1946, p.20).

A "moderna cidade" aparecia estampada pelas mais variadas adjetivações superlativas. Era um feito, uma grande realização digna de grandes homens. Assim veiculava-se, em várias produções textuais, a cidade, seus governantes e o seu povo. A 
construção desse ideário, uma obra sempre inacabada, necessitava constantemente de novos e promissores alicerces. Nesse contexto, pode-se dizer que as diversões e os esportes serviram a um projeto simbólico de edificação de um ideal que, por muitas vezes, escapava da fluidez de um cotidiano necessariamente paradoxal.

\section{A Superação do Tédio na "Filha Da República": O Incentivo aos Divertimentos e aos Esportes como Estratégia de Afirmação da Modernidade Belo-Horizontina}

As percepções progressistas anteriormente mencionadas sobre a cidade conviveriam com outras antagônicas, produzidas em período similar. Para outros olhos daquela época, Belo Horizonte ainda era uma cidade simples, rotineira, poeirenta, vazia. Um dos motivos que fundamentava estas designações (e que se constituiria em uma busca constante para se reverter tal quadro representativo) era a constatação da falta de divertimentos. Pode-se inferir, até mesmo, que esta percepção embasaria os investimentos futuros da administração local, haja vista o reconhecimento, já naquele momento, do lazer e do entretenimento como um forte mercado em desenvolvimento e de uma importante visibilidade que suas práticas detinham na construção simbólica da modernidade dos centros urbanos brasileiros. Ainda nos 1930 e 1940, a nova capital dos mineiros procurava superar os ranços de um provincianismo incômodo, que emperrava os intentos modernizadores propostos desde o momento de sua criação. Em princípios da década de 1930, uma das reportagens a designou como a "cidade do tédio".

Bello Horizonte é denominada, com razão, a cidade do Tedio. Pobre de diversões, a cidade, á noite, é um enorme amontoado de casas adormecidas, sobre ruas desertas e sombrias. Temos por unica diversão o cinema, que não passa de um monopolio revoltante, onde tudo é levado em conta, menos o interesse do publico, que é 
escorchado impiedosamente. [...] E mau cinema, porque o commum dos programmas é constituído de fitas já ha varios anos exhibidas, em reprises enfadonhas e soporíferas (CIDADE..., 1933, p.29).

Em outro texto, fruto da reprodução de uma conversa (possivelmente fictícia) entre um mineiro e um carioca que estava de visita a Belo Horizonte, desnudam-se características ambíguas da cidade no mesmo período.

Espirito investigador, pipocava-me de perguntas acerca da actualidade e progresso de Bello Horizonte. E eu satisfazia-o, falando-lhe do CineBrasil e seus milhares de poltronas; da média de oito casas construídas diariamente; do que representaria a futura ligação ferroviaria com a Victoria-Minas, etc., etc. Passavamos, então, pelo salão de engraxar e convidei-o a lustrarmos os nossos sapatos. - De facto, a poeira aqui é mais amarella do que no Rio, respondeu-me elle. Lá, o asphalto vira em pó côr de cinza (ESPÍRITO..., 1933, p.1).

Para o interlocutor principal, a construção do Cine-Brasil era sinônimo de adiantamento, motivo de fala orgulhosa, que parecia colocar em um mesmo parâmetro de comparação a construção da ferrovia. Em contrapartida, após o anúncio do progresso, mencionava-se a poeira amarela da cidade, aparentemente menos "evoluída" do que a do Rio de Janeiro. Completando as ambiguidades, ao final da reportagem havia o seguinte diálogo, iniciado pelo amigo carioca: "- Não ha mais nada de interessante e typico por aqui? - Como não! Contestei eu. Tivemos uma onça que comia cabritos alli pelo bairro da Floresta. E houve mais: um phantasma, fantasiado de moça, apparecia em outro bairro: na Serra" (IDEM). Em meio à anunciação do progresso e da civilidade, emergiam onças e fantasmas no cotidiano citadino.

Nesse contexto, o cinema parecia figurar como uma das mais importantes diversões de Belo Horizonte na década de 1930, seja pela relevância que adquiriu por si mesmo, seja pela escassez de outras opções, como apregoavam alguns periódicos. Em outra reportagem, o Cine Brasil aparecia destacado como uma das "melhores casas de 
diversão da America" (DIAS, 1933, p.6). O edifício Brasil, onde ficava tal cinema, foi citado na ocasião de sua construção como um "marco na historia do commercio de Minas Gerais [...]”, assinalando “a epoca da evolução do negociante mineiro" (IDEM). Entretanto, o emblema de desenvolvimento citadino representado pelo cinema também foi protagonista de uma crônica provocadora que colocava em xeque o seu caráter progressista, as possibilidades desse divertimento na capital e a própria ideia de evolução da cidade. Intitulado "Bilhete para Walt Disney", o texto reclamava a ausência do personagem Mickey Mouse em Belo Horizonte:

O que não se compreende, Walt Disney, é que seu 'little mouse' appareça somente para determinados privilegiados. Não sei si você ja teve conhecimento de um facto gravíssimo: os seus desenhos, que marcam uma época na cinematographia; os seus desenhos, que vão perpetuar o seu nome, tão notaveis e apreciados elles são, não vêm a Bello Horizonte. Ninguém, até hoje, nesta capital explicou a razão por que Mickey ainda não nos fez a sua primeira visita, tão ansiosamente esperada. E eu fico matutando, matutando, até que vêm á cabeça questões de sciencia das finanças, como seja a da concorrência [...] (BIMBO, 1933, p.3).

$\mathrm{Na}$ década seguinte, o cinema ainda teria centralidade nas discussões acerca dos divertimentos da cidade. O simbolismo que o atribuía ao progresso permanecia, como é o caso da reportagem que enaltecia a construção de inúmeras salas em diversos bairros: “[...] Cinemas que colocam a capital mineira à altura de qualquer outra capital [...], no trabalho de nosso progresso e de nossa civilização" (ENTREGUES..., 1943, p.90). Anunciava-se que Belo Horizonte, por meio do cinema, poderia emparelhar-se, "sem nenhuma dúvida, com as principais capitais da América do Sul” (IDEM).

O cinema chegou a ser mote de outra reportagem que tornaria a afirmar que Belo Horizonte era uma "cidade sem divertimentos", pois não havia "nada além do cinema". Ao criticar as carências observadas no teatro e na música, o autor do texto contrastava o 
crescimento "vertiginoso" da capital com a escassez de iniciativas no "terreno cultural" (CINQUENTENÁRIO..., 1947, p.1).

[...] O ambiente musical não se movimenta mais do que uma vez por mês, através do concerto da Orquestra Sinfonica. E onde está o teatro mineiro? Praticamente não existe. Aí estão muitas vocações dramáticas sem uma 'chance', de vez que não se organiza um movimento sério no sentido de evitar que o teatro na Capital de Minas seja uma sequencia de avanços e recuos. Muito entusiasmo e idealismo nos artistas universitários, mas suas iniciativas não tem continuidade. E os poderes púbicos não apoiam em nada. Não é possível fazer milagres. E Belo Horizonte, que está crescendo vertiginosamente, não tem progredido no terreno cultural. Chegou a um elevado grau de desenvolvimento intelectual, mas este ha muito se encontra estagnado, á espera de que um sôpro vigoroso e sadio de renovação arraste para bem longe as águas do marasmo e da mediocridade (IDEM).

Alguns anos antes, outra reportagem já havia sinalizado a ausência de um teatro popular na cidade, como uma "estranha lacuna em nosso progresso" (MIRANDA; CASTRO, 1943, p.37). Em Belo Horizonte, designada como "centro de convergência de grande número de forasteiros de todo o Estado" esta falta fazia-se notar, na opinião do colunista, pelas pessoas que visitavam a capital. O texto mencionava a construção do Palácio das Artes, iniciada em 1941 durante a administração do prefeito Juscelino Kubistchek, como importante feito, mas que, "ao que tudo indica, [...] se destina à apresentação de temporadas líricas e de conjuntos de fama internacional, cujos ingressos provavelmente não estarão ao alcance de todas as classes sociais" (IDEM).

Reportagens como estas demonstravam um cenário de ambiguidades. Havia certa ressonância nas vozes que promulgavam e atestavam o progresso belohorizontino. Porém, havia dissonâncias; vozes que também construíam outra percepção da cidade que, por vezes, escapava dos intentos de seus projetos inaugurais. E, nessa conjuntura, formavam-se as mais variadas combinações descritivas. Em uma das edições da revista Bello Horizonte, do ano de 1937, percebe-se uma mescla de 
características bucólicas com propriedades sinalizadoras do que se compreendia como nova etapa de progresso:

\begin{abstract}
Bello Horizonte, esta cidade bonita e encantadora que os poetas cantam em versos e os compositores em música - cidade das árvores verdes e frondosas, das montanhas majestosas e das avenidas largas e bem traçadas, é também neste momento a cidade progresso, vertigem, dynamismo - trabalho. As ruas e avenidas são rasgadas em todas as direções; o asphalto avança célere por todos os lados; o borborinho das ruas é quasi um delírio - as fabricas erguem para as alturas as suas cupolas negras e as chaminés enfumaçadas - as industrias brotam e florescem aqui e acola [...] (OS PLASMADORES..., 1937, p.32).
\end{abstract}

Em reportagem publicada na Revista Minas Tenis, na década seguinte, observase combinação semelhante.

[...] Belo Horizonte! Não! Não é uma cidade. Porém um bosque em flor crivado de vivendas! Dois gigantes da prosa, e um jornalista e um poeta. Já disseram de ti as frases mais formosas. És 'cidade vergel', es a 'cidade reta', 'miradouro dos céus', 'acrópole das rosas'... Retilineas, sem fim, as ruas e avenidas. Multiplicam-se, vão para todos os lados. E, numa sucessão de vivendas floridas. Espalham-se, povoando os bairros sossegados [...]. É o progresso, com seus tumultos e rumores - a rodar, buzinar, veículos infrenes. Garotos de jornais, pregões de mercadores. E das fabricas, rouco, o apito das sirenes (TURISMO, 1944, pp-30-31).

A maior parte das produções textuais investigadas centraram suas narrativas na descrição e no enaltecimento de atributos contemporâneos da cidade, ou seja, do período histórico em que as próprias reportagens se inseriam. Os elogios ao seu desenvolvimento ocupavam número significativo de páginas nos variados impressos, especialmente nas revistas, com insistente destaque às ações governamentais. $\mathrm{Na}$ opinião de Barreto (1944, p.42), o início do maior surto de progresso de Belo Horizonte se deu a partir de 1935, no governo municipal de Otacílio Negrão de Lima (19351938/1947-1951) e na gestão estadual de Benedito Valadares (1933-1945). 
Outras reportagens, entretanto, conferiam à municipalidade de Juscelino Kubitschek (1940-1945) a maior façanha progressista da história belo-horizontina. A cidade chegou a ser denominada "majestosa capital" de "curta existência", que poderia se "enfileirar entre as maiores metrópoles do país, em todos os setores da atividade humana" (BELO HORIZONTE..., 1942, pp. 74-75). Um destaque desta publicação é a referência à inserção de Belo Horizonte no "século do ferro e do cimento". Tal designação se assemelha aos dizeres de Carvalho (2005) em uma de suas abordagens sobre a história de Minas Gerais. Para o autor, pode-se destacar três fases no desenvolvimento do estado, denominadas por ele de: a "Minas do ouro", a "Minas da terra" e a "Minas do ferro". A primeira refere-se ao passado colonial, representado, especialmente, pelo ciclo do ouro da antiga capital Ouro Preto. A segunda destina-se a caracterizar a fase posterior à implantação da república que, mesmo sob os auspícios do progresso e do desenvolvimento industrial, manteve-se arraigada na produção agrícola e nas grandes oligarquias. Já a terceira sinaliza o momento em que Minas abre-se aos investimentos externos e incrementa o setor secundário e terciário de sua economia. Para o autor, as investidas da "Minas do ferro" se concretizaram especialmente na década de 1940.

[...] a capital mineira de hoje pode oferecer aos olhos de seus visitantes o atestado vivo de sua integração no século do ferro e do cimento, cortando os céos com seus magníficos edifícios públicos e particulares, deliciando o homem com o espetáculo de suas belíssimas praças, suas largas e bem calçadas avenidas, suas modernas e confortáveis casas de diversões e todo esse gigantesco aparelhamento que a mão do homem sabe levantar, para a satisfação absoluta de suas necessidades no vertiginoso tempo que vivemos (BELO HORIZONTE..., 1942, p. 74-75).

A necessidade de se estabelecer parâmetros comparativos com outras metrópoles do país e do mundo era outra característica muito presente nas reportagens. Um olhar 
"do outro" e um olhar "para o outro" se faziam frequentes nas narrativas midiáticas, com destaque, no texto supracitado, para as "modernas e confortáveis casas de diversão". Assim, a concretização da modernidade, do progresso e da civilização adquira sentido, sobretudo, na comparação. Nesse caso, ao se compreender esses predicados como elementos distintivos que se desejava veicular, pode-se considerar que as suas propriedades só existiam "na e pela relação, na e pela diferença" (BOURDIEU, 2007, p.212). Em edições da revista Bello Horizonte observa-se, corriqueiramente, tal empreitada. A cidade, designada como "o mais eloquente e vivo attestado da capacidade realizadora dos mineiros, não só pela construção da urbs como também pelo acelerado crescimento" (BELLO HORIZONTE..., 1940, p. 20-21), vangloriava-se por alinhar-se “entre as primeiras cidades brasileiras, pela sua população, pelo seu progresso material, pelos serviços públicos de toda espécie, pelo desenvolvimento cultural” (IDEM).

Em outro registro, a capital mineira destacava-se por se ombrear "com as mais adiantadas cidades do país e mesmo do continente" (REGISTRO, 1943, p.3), constatação que se devia à dotação de "todos os recursos e meios de confôrto da vida moderna, [...] um apreciavel parque industrial, extenso e intenso comercio, grande centro educacional, [...] associações e organizações de pesquisas e estudos” (IDEM). Em outra produção textual, a menção à uma possível recepção externa é aclamada: “A cidade, com seus encantos, com sua vida alegre e festiva, com seu clima admirável, representa um centro como poucos que existem no Brasil. [...] Em curto prazo, se transforma no que os paulistas chamam de "Capital da Arte do Brasil" (BELO HORIZONTE..., 1944, p.58-59). 
A importância do olhar externo também se mostrava relevante na revista Alterosa. Em um de seus artigos tem-se uma dimensão mais ampliada dessa produção discursiva.

\begin{abstract}
Em dezembro de 1947 Belo Horizonte completará 50 anos de existência. Meio século apenas de vida, e já a nossa Capital esplende como legítima metrópole. Surpreende o viajante que, vindo dos países mais civilizados do mundo, toma contato com as suas maravilhosas realizações em todos os setores da civilização. [...] $\mathrm{O}$ visitante que chega à Belo Horizonte pela primeira vez, surpreende-se de verdade com o seu progresso. E depois que toma contato com as realizações que a cidade apresenta, depois que sente toda a intensidade de sua vida moderna, outras são as palavras de admiração que emprega [...]. Lembramo-nos bem do que tem dito ultimamente as figuras de alta representação política, científica, cultural e econômica na Europa e na América do Norte, ao expressarem sua admiração pelo que lhes foi mostrado em nossa Capital (BELO HORIZONTE, 1946, p.134).
\end{abstract}

Em outra reportagem chamava-se a atenção do leitor para a sua responsabilidade na conservação do status que a cidade intentava construir: "E que, em cada ano, o belorizontino cuide da modernização desses programas, fugindo aos detalhes provincianos e realizando o que de fato possa atrair o público" (CINQUENTENÁRIO, 1947, p.1).

A maior parte dos registros mencionados insere-se no período de governo municipal de Juscelino Kubitschek ou se localizam em datas muito próximas à sua gestão. Na revista Minas Tenis Juscelino foi mencionado como "o animador da cidade" (JUSCELINO KUBITSCHEK..., 1944, p.12). Na reportagem que sinalizava tal desígnio o prefeito era enaltecido por sua "capacidade realizadora" mesmo durante os percalços da Segunda Guerra Mundial, ao possibilitar a Belo Horizonte o "mais vertiginoso impulso de progresso de toda a sua história" (IDEM).

A construção do conjunto arquitetônico da Pampulha é um dos maiores exemplos citados nos periódicos, junto a medidas de saneamento, ao incremento da área 
asfaltada da cidade e ao desenvolvimento do parque industrial. Em reportagem da revista Alterosa, a edificação da Pampulha é enumerada junto aos empreendimentos realizados para "dotar a Capital de todos os requisitos de uma moderna metrópole" (BELO HORIZONTE..., 1942, p-74-75). Para Bahia (2008, p.7), a Pampulha se constituía como uma "ilha de modernização e sociabilidade na capital, nos anos 40, quando ainda não existiam certos tipos de práticas culturais ao ar livre, como jantares dançantes e esportes náuticos”. A ideia surgiu a partir da criação de um lago artificial por meio do represamento das águas do Ribeirão Pampulha, localizado na região norte da cidade, e envolvia a transformação daquele espaço em "centro turístico e de lazer para a cidade" (BAHIA, 2008, p.16). O conjunto arquitetônico foi inaugurado em 1943, compondo-se, ao redor da orla do lago artificial, das edificações do Cassino, do YatchClub, da Casa do Baile e da Igreja de São Francisco de Assis.

Em 1942, quando ainda se encontrava em construção, o complexo foi descrito como "a mais risonha realização do velho sonho belo-horizontino" (BELO HORIZONTE..., 1942, p.74-75). Ao mencionar o aspecto de suas obras, o texto anunciava:

[...] Quem visita hoje aquele recanto da cidade, tem a impressão de ver nascer uma Copacabana dentro de Belo Horizonte. [...]. As obras do Casino, quasi terminadas, o Clube, o Baile, suas lindas casas de campo, tudo concorre para imprimir a esse novo bairro o aspecto aristocrático e pitoresco de uma bela miragem transformada em realidade pela ação do homem (IDEM).

O jornal Estado de Minas noticiou, em uma grande reportagem, a inauguração da Pampulha, descrevendo o feito como o "coroamento de uma série de realizações da administração em benefício da capital, fixando um marco decisivo no progresso da metrópole mineira" (BRILHANTES..., 1943, p.3). A notícia citava o "apoio decisivo" do governador Benedito Valadares e as numerosas atrações do complexo, "todas elas de 
interesse para a capital, cujo progresso dia a dia se torna mais crescente, reclamando, por isso mesmo, realizações modernas, capazes de canalizar para Belo Horizonte a atenção dos visitantes" (IDEM).

Nos escritos de Barreto (1944, p.42), a Pampulha também chegou a ser descrita como a "Copacabana de Belo Horizonte", evidenciando, novamente, uma necessidade comparativa com outras cidades brasileiras, especialmente aquelas consideradas como importantes centros metropolitanos, neste caso, o Rio de Janeiro. Na revista Minas Tenis há ainda a menção a uma visão estrangeira sobre a obra, como se lê na seguinte nota: “[...] o grupo arquitetônico da Pampulha constitue o que, no gênero, se encontra de mais original e avançado em todo o mundo - e esse é o testemunho de técnicos autorizados dos Estados Unidos" (BELO HORIZONTE...,1944, p.10). O olhar advindo de outros lugares era constantemente mobilizado como forma de se atestar os sucessos dos empreendimentos realizados na capital. Uma obra voltada, dentre outros objetivos, para o divertimento da aristocracia citadina era, assim, descrita como uma das mais importantes do município e do estado.

A necessidade de tornar Belo Horizonte visível e pertencente a um circuito de cidades "avançadas" era uma premissa importante que encontrou ressonância na figura do então prefeito, entre os anos de 1940 e 1945: “[...] o sr. Juscelino Kubitschek tem sido o administrador que colocou a capital no mapa, como centro do maior conjunto moderno do país, ou melhor, do mundo. A Pampulha é a afirmação categórica deste conceito" (BARRETO, 1944, p.42). Como se percebe na referida reportagem, os ousados imaginários progressistas da cidade ultrapassavam as fronteiras do país, ao menos nas formas narrativas. 
Por ocasião do aniversário de Belo Horizonte, a revista homônima publicou um extenso texto comemorativo, com destaque às ações governamentais realizadas em âmbito municipal e estadual. Nele se encontram elogios à "metrópole madura" e ao "assombroso desenvolvimento" da "cidade moça" de "traçado moderno" (O ANIVERSÁRIO..., 1944, pp.52-55).

[...] é de justiça afirmar que esse aceleramento ganhou no último decênio uma expressão nova: nesse período se fez mais para o desenvolvimento de Belo Horizonte do que em toda a sua vida passada. [...]. Hoje ninguém pode mais negar que as grandes civilizações se formam em torno dos grandes centros. Estes se tornam, assim, pontos irradiadores de progresso e de civilização. Dotando a capital de Minas de todos os requisitos de uma cidade moderna, o governador Benedito presta, pois, um benefício á comunidade mineira [...]. Na execução desse seu magnífico plano administrativo, o chefe do governo mineiro tem encontrado no prefeito Juscelino Kubitschek um auxiliar a altura do alto cargo que lhe foi confiado (IDEM).

$\mathrm{Na}$ reportagem em questão, o principal exemplo mencionado foi novamente a Pampulha, retratada como o "centro de turismo mais completo e mais belo do Brasil" (IBIDEM). Percebe-se o destaque conferido aos divertimentos e ao esporte, um dos símbolos da nova sensibilidade que se anunciava.

Ao redor de um grande lago artificial, erguem-se agora pitoresca vivendas e centros de esportes e diversões: o Cassino, a Casa do Baile, o Yatch-club, lugares onde os visitantes passarão horas agradáveis de repouso, divertindo-se e praticando esportes [...], em contato direto com uma natureza admirável e de paisagem pitoresca (IBIDEM).

As possibilidades de concretização do sonho da modernidade belo-horizontina estavam intimamente relacionadas a um desenvolvimento sólido da cidade (comumente medido pela extensão de área asfaltada, pelo número de edifícios e arranha-céus construídos, pela expansão do saneamento e pelo incremento da parte industrial) e também aos costumes de seus moradores. Neste último caso, dentre outros quesitos, o 
progresso fazia-se mensurável pelo número de cinemas, casas noturnas e de jogos, campos de futebol, clubes e pela constatação da ampliação do gosto do belo-horizontino pela prática de esportes e pelo divertimento ao ar livre.

A revista Alterosa, ao realizar um balanço sobre as ações efetuadas em Belo Horizonte entre os anos de 1940 e 1946 demonstrava esta tendência, também perceptível em outros impressos. A reportagem em questão destacava a edificação de 3.850 prédios nesse intervalo de tempo, ressaltando a proeza do feito concretizado em “plena guerra [...], com a falta de cimento, com o racionamento do ferro e de todos os demais óbices [...]" (BELO HORIZONTE..., 1946, p.134). O texto, que retratava Belo Horizonte como "uma cidade nova e bonita, grandiosa e movimentada, [...] justo motivo de vaidade para o Brasil”, seguia enfocando o panorama de construções no ano de 1946 - “Atualmente a capital dispõe de 37.525 prédios [...], mais de 60 novos arranha-céus estão com suas obras iniciadas" - e o contingente populacional: "a cidade aproxima-se dos 300 mil habitantes" (IDEM).

Inseridas nesse diagnóstico, outras características foram sinalizadas como indicativo de desenvolvimento no ano de 1946, como a existência de vinte cinemas, um teatro, um circo, quatro dancings, seis jornais diários, vinte revistas de diversas periodicidades, três estações de rádio e vinte e oito livrarias. Entre estas referências, destacava-se a prática esportiva:

Também os esportes e a cultura física encontraram em Belo Horizonte um dos centros mais adiantados do Brasil. Dispomos atualmente de 8 grandes clubes, magnificamente aparelhados, e dezenas de clubes menores. Nove quadras de tênis, 6 quadras de bola ao cesto. Sete para vôlei. Um moderníssimo campo para ginástica e brinquedos infantis. Um campo gramado para ginástica e jogos. Cinco piscinas (não contando as particulares), 3 grandes estádios de futebol, 1 pista de atletismo, 1 ring para luta, 1 stand para tiro ao alvo e outro para tiro ao vôo. Nada menos de 21.449 pessoas se acham inscritas nas associações de cultura física de nossa capital (IBIDEM). 
Reportagens como esta seriam demonstrativas da importância adquirida pelos divertimentos e pelos esportes na administração pública e na cultura belo-horizontina. Um dos símbolos do adiantamento da cidade estava posto nas atividades esportivas e de diversão em geral, nos espaços e nos equipamentos disponíveis, mesmo que sua avaliação tenha se restringido, no texto em questão e em outras reportagens, em expressões meramente quantitativas.

Diante desse contexto, torna-se necessário detalhar algumas características do cenário político que se delineava naquele momento. O mandato de Juscelino Kubitschek na prefeitura de Belo Horizonte ocorreu sob nomeação do então governador de Minas Gerais, Benedito Valadares Ribeiro, que, por sua vez, foi indicado ao posto de chefe do estado por Getúlio Vargas, presidente do Brasil entre os anos de 1930 e 1945, após o golpe instaurado em 1930. Durante o período de governo varguista, que manifestou suas vertentes mais autoritárias e centralizadoras com a política do Estado Novo (19371945), o país viveu um processo de intensa industrialização, de estruturação da administração do Estado e de exacerbação do nacionalismo, via "estratégia nacional de desenvolvimento" que, dentre outros pressupostos, instituía uma ideia de refundação da nação e de transformação do Brasil em Estado-Nação autônomo (BRESSER-PEREIRA, 2012, p.108). Nessa perspectiva, também ganhariam destaque as políticas trabalhistas propostas por Getúlio, com as primeiras regulamentações referentes às profissões e com a posterior criação das leis trabalhistas em 1943. Entretanto, os intentos estado-novistas foram permeados pela criação de instituições autoritárias, por proclamações de decretos-lei e pela ação contínua de órgãos de censura em diversos aspectos da vida social. Nesse quadro de ações, tentativas de se modificar o corpo e os costumes do 
brasileiro e de se criar uma nação forte nos moldes dos governos nazifascistas foram também abalizadas.

Inserido nas orientações políticas do Estado Novo (1937-1945), o governo de Valadares (1933-1945) destinou ao esporte especial relevância na tarefa de 'reformular' a estrutura física e o caráter da população mineira. Inúmeras praças de esporte foram construídas em diversos municípios com a finalidade explícita de educar os jovens para uma nova sensibilidade, calcada no ideal valorativo do exercício físico cotidiano como chave para o progresso, para a eugenia e para o fortalecimento do estado e da nação. A edificação destas praças deveria seguir como exemplo a experiência concretizada na fundação do Minas Tênis Club, datada do ano de 1935. A idealização do clube belohorizontino contou com o apoio de Benedito Valadares e de Getúlio Vargas, que estiveram presentes na inauguração de sua praça de esportes, no ano de 1937. O Minas foi amplamente divulgado como exemplo da energia mineira e como "templo de cultura e aperfeiçoamento da raça” (UMA..., 1939, p.52-53).

As produções discursivas presentes nos periódicos auxiliam na formação de um contexto compreensivo. Havia um âmbito maior de influência e de circulação de informações e de "sentimentos" que envolviam noções de pertencimento identitário, possibilidades comparativas e disputas de poder. Pode-se inferir que o recrudescimento da veiculação de determinados esportes e de formas de divertimento (assim como a construção de equipamentos) em Belo Horizonte caminhou junto com a própria utopia da modernização da cidade, fez parte dela e alimentou a esperança da construção de uma nova sociedade. Se é impreciso afirmar que Belo Horizonte alcançou, de fato, seus objetivos progressistas nas décadas pesquisadas, não se pode negar uma veiculação 
midiática que visava noticiar a cidade como urbe passível de ser classificada como moderna.

Desta forma, um importante intento dessa premissa qualificadora perseguiu os noticiários belo-horizontinos nos anos 1930 e 1940: a tentativa de consolidação de uma cidade esportiva e rica em diversões. Uma reportagem publicada na revista Alterosa sintetiza, propriamente, o objetivo posto na prática esportiva:

Belo Horizonte, cidade moderna em todos os magníficos aspectos de sua vida, tinha, forçosamente, que ser desportiva, preparando o vigor e a força física de sua juventude com esse mesmo entusiasmo que cuida do seu desenvolvimento e progresso espiritual (A MULHER..., 1942, p.34).

De maneira semelhante à outras possibilidades de entretenimento e diversão, a exemplos dos cinemas, das casas noturnas e de jogos e, especialmente, da amplitude de vivências prometidas pelo Complexo da Pampulha, os esportes, de maneira geral, constituíram-se em uma alternativa fértil que demonstrava a capacidade modernizadora da cidade para além do campo econômico, como parte de um capital cultural (BOURDIEU, 2007) necessário ao desejo de formação integral de uma metrópole avançada. Nessa perspectiva, a prática de esportes foi amplamente difundida, a exemplo do que já vinha acontecendo em outras cidades do mundo e do Brasil, embora seja necessário considerar que Belo Horizonte (fundada apenas em 1897) ainda se esforçava para se apropriar dos códigos que eram veiculados no contexto de centros urbanos mais consolidados (SOUZA NETO; SOUTTO MAYOR, 2014).

Sevcenko (1994, p.80) menciona "uma febre esportiva que varreu o mundo a partir das duas últimas décadas do século XIX”. O autor relaciona o incentivo da prática esportiva a um intento de adaptação à nova vida social, produtiva e tecnológica: "para 
tornarem-se velozes e adaptadas às modernas fontes de energia, as pessoas tinham de ser fisicamente condicionadas e psicologicamente motivadas" (1994, p.82). O ethos esportivo, relacionado às finalidades progressistas atribuídas ao esporte, fez-se presente em diversas cidades brasileiras, como Manaus, Maceió, Vitória, Salvador e Recife, em finais do século XIX e princípios do século $\mathrm{XX}^{8}$. No entanto, os periódicos belohorizontinos centraram suas atenções nos acontecimentos do eixo Rio de Janeiro-São Paulo, tomado, corriqueiramente, como uma referência. Nesse contexto de influências, várias publicações oriundas da capital mineira conferiam a Minas Gerais o título de terceiro centro esportivo do país, em uma eterna e intangível competição por prestígio, reconhecimento e visibilidade.

Percebe-se, por meio de investigações realizadas por diversos pesquisadores ${ }^{9}$, importantes relações estabelecidas entre as prerrogativas de uma modernidade almejada e o desenvolvimento do fenômeno esportivo em várias cidades brasileiras. Melo (2010, p.15) sinaliza que as configurações sociais que emergiram em um panorama onde se estabelecia como importante a pretensão e o desejo de ser moderno estabeleceram “múltiplos diálogos com um cenário internacional, em parte se aproximando (ou buscando se aproximar) de uma representação macro/alheia ou/e relendo-a pelas lentes locais".

\section{A Modernidade Relativa e a Intangibilidade de uma Busca Sem Fim}

À racionalidade e ao cartesianismo presentes no ideário de construção de Belo Horizonte, ícone do republicanismo à mineira (progressista e conservador, como

\footnotetext{
${ }^{8}$ Como exemplo, tem-se os seguintes periódicos, encontrados na base de dados da Hemeroteca da Biblioteca Nacional do Rio de Janeiro: O Sport (Salvador, 1889); O Sport (Recife, 1895); Correio Sportivo (Manaus, 1910); O Sport (Vitória, 1915), Penedo Esportivo (Maceió, 1922).

${ }^{9}$ Podem ser citados os textos publicados na coletânea "Os sports e as cidades brasileiras: transição dos séculos XIX e XX”, organizado por Victor Andrade de Melo (2010).
} 
ponderou Carvalho, 2005), somou-se a percepção da necessidade de incremento da oferta de atividades de divertimento e de esportes para o delineamento de um novo conjunto de hábitos. Entretanto, os intuitos de idealização da cidade-capital comportaram suas ambiguidades, vislumbradas nas próprias páginas dos periódicos que, ora buscavam sinalizar a inserção da cidade em uma modernidade desejada, ora dedicavam-se enfaticamente a tecer críticas sobre a estrutura urbana da capital, sobre as possibilidades culturais (compreendidas, comumente, como o acesso à diversão e às manifestações artísticas e esportivas) e sobre os costumes provincianos de seus moradores. Havia tensões que se manifestavam entre a solidez de um projeto arquitetônico e a fluidez da cidade em seu cotidiano; entre ideais, sonhos e ilusões préestabelecidos e o plano das vivências diárias.

O início da década de 1930 ainda era marcado pelas ambiguidades de uma cidade que buscou romper com os resquícios do passado colonial de Ouro Preto (representado pelas vozes do ouro) mas que, mesmo sob a bandeira do republicanismo e do liberalismo, fez ecoar, com mais força, as vozes conservadoras da terra: ordeira, equilibrada e familística (CARVALHO, 2005). Somente no final da década citada, Carvalho (idem, p.65) sinaliza uma mudança no cenário econômico, "quando Belo Horizonte se tornou centro da política industrializante”. Para o autor, nesse momento, abre-se caminho, efetivamente, para a voz do ferro, a do progresso. Também para Arruda $(2012,117)$, as tentativas de ingresso na modernidade esbarraram-se em um estado que ainda detinha vocações agrárias, situação que somente seria "ultrapassada em meados do século XX”.

Brandão $(2009$, pp.100, 101) retrata uma cidade "contaminada por nostalgias e fantasias invadindo seus contornos retos $[\ldots]$ ”, traçada para ser a cidade das esquinas e 
das largas avenidas, "as quais, até a década de 1920, eram feitas de terra e para carros de boi, cabras e redemoinhos de pó vazio entre seus poucos habitantes”. O autor designa sua "modernidade" como "vacilante", "débil", "insossa", "fraca" e "tardia", "que suspeita de si própria e leva essa suspeita pelo futuro adentro, como consciência crítica de si".

Bomeny (1994, p.17), ao abordar o modernismo mineiro e sua expansão para além dos limites do estado, capitaneada por intelectuais como Carlos Drummond de Andrade, Gustavo Capanema, Rodrigo Melo Franco de Andrade e Francisco Campos, nomes que se tornariam figuras importantes do governo de Getúlio Vargas (sobretudo no que tange a projetos educacionais), observa que estes intelectuais se ocupavam da reflexão "sobre ser moderno, construir uma nação, e integrar o Brasil no 'Concerto da Nações"”. No entanto, Bomeny tece o seguinte questionamento: "Seria o modernismo mineiro moderno? A autora ainda explora a "tensão entre os anseios universalistas e os limites que a provinciana Belo Horizonte impunha" como fator importante para se pensar a construção de "um conjunto harmonizador no "ser mineiro"”. A tensão entre modernidade e provincianismo seria uma constante na história belo-horizontina. Os anos 1940 ainda apresentariam a força dessa ambiguidade "incômoda", reverberada em vários aspectos da vida social, dentre eles, os esportes e os divertimentos.

Mello (1996, p.13) sinaliza que esta tensão esteve presente desde o momento de inauguração da cidade, pois a criação de uma nova capital não representou uma "ruptura do tipo novo/velho, moderno/antigo, mas uma recomposição do tempo histórico dentro de uma legitimação da justaposição tradição/futuro". Nesta perspectiva, Arruda (2012, p.118) enfatiza que rapidamente se "demonstraram as distâncias entre seu planejamento e execução". Ao se referir também à cidade de La Plata, o autor as considera provas do 
hiato existente entre a idealização de "cidades-modelo" e as possibilidades de apropriação e ocupação, ou seja, "as distâncias presentes entre a cidade ideal e a cidade real". Ao mesmo tempo, experiências deste tipo demonstram como os discursos "sobre o que era ser moderno no período influenciaram comportamentos e, de certa forma, instituíram imaginários até hoje perceptíveis no senso comum (idem)".

As ambiguidades presentes nas páginas das revistas e dos jornais demonstram a relatividade das noções de modernidade, moderno e modernização, vastamente utilizadas nas produções textuais do período analisado. Outras designações, que sugeriam um tom semelhante de qualificação, também foram vislumbradas, como "civilização", "progresso", "vertigem", "rapidez", "intensidade". O uso frequente e repetitivo dessas expressões não pode ser compreendido como ação despropositada; ao contrário, formam parte de uma proposição discursiva interessada.

O que se compreende como moderno, modernização ou modernidade prescinde sempre de um referencial. Nas palavras de Carvalho (2012, p.32), os termos devem ser definidos por "um momento determinado no tempo" e circunscritos "em uma situação histórica e cultural específica, de forma a favorecer a percepção e o entendimento acarretado por relações contextuais [...]”. O autor chama a atenção para uma situação importante: “os termos não podem ser confinados em um conceito estrito previamente determinado de natureza transistórica, pois requerem um contexto, ou circunstancialização histórica, em que sua definição emerge tornando-se operatória" (idem). Para Berman (2007, p.24), a modernidade é um tipo de experiência vital “experiência de tempo e espaço, de si mesmo e dos outros, das possibilidades e perigos da vida - que é compartilhada por homens e mulheres em todo o mundo". 
[...] o "ser moderno" implica "uma visão aberta e abrangente da cultura; muito diferente da abordagem museológica que subdivide a atividade humana em fragmentos e os enquadra em casos separados, rotulados em termos de tempo, lugar, idioma, gênero e disciplina acadêmica (BERMAN, 2007, p.11).

As considerações de Charaudeau (2006, p.215) caminham em direção semelhante, ao propor uma compreensão da modernidade como um tipo de imaginário sociodiscursivo. Para o autor, a modernidade não é estabelecida por setores de atividades (tais como o político, o econômico, o literário ou o artístico) que rompem com um suposto período precedente. Em suas palavras, trata-se

[...] de um conjunto de representações que os grupos sociais constroem a propósito da maneira como percebem ou julgam seu instante presente, em comparação com o passado, atribuindo-lhe um valor positivo, mesmo quando o criticam. Pode-se, portanto, aventar a hipótese de que, a cada momento presente de sua história, os grupos sociais se dotariam de um imaginário de modernidade, sempre tomando como base a época precedente e procurando legitimá-la: a cada vez está em jogo a legitimidade de uma maneira de ser e de viver, uma visão nova do mundo (idem).

Charaudeau (2006, p.210) observa, ainda, características que seriam importantes para se pensar o contexto belo-horizontino: a ideia de modernidade como uma representação comparativa que visualiza no momento presente "um estado de saber superior em relação ao passado". Nesse caso, o autor considera o imaginário sociodiscursivo da modernidade (junto com o da tradição) como um dos mais "recorrentes e mais propícios a alimentar a dramaturgia política". A recorrência a esse imaginário é bastante perceptível nas reportagens, sobretudo nas que enaltecem as ações dos políticos que governaram Belo Horizonte e Minas Gerais no período em questão. Há ainda a presença de outras estratégias citadas pelo autor (2006): argumentos que se fundamentam na razão (representados pelos números do progresso) e na paixão (no 
apelo à identidade mineira e à necessidade de o cidadão contribuir para que a cidade alcance o grau de adiantamento de outras metrópoles).

Ações como estas compõem uma materialidade que alimenta, assim, a produção do imaginário sociodiscursivo da modernidade, em um tempo específico. Neste caso, trata-se de um momento em que as prerrogativas de construção de uma capital que se queria moderna se articulavam a determinados imaginários reguladores da vida citadina e a determinadas ações políticas, o que envolvia, também, as práticas esportivas e as possibilidades de diversão. Propondo-se uma analogia com o conceito de "tradição inventada" cunhado por Hobsbawm (1997), pode-se pensar em uma "modernidade inventada", dada a urgência de se apregoar a inserção da cidade nesse critério de classificação, de uma maneira bastante artificial e com discursos repetitivos, servindo como um importante elemento de coesão social.

A cidade do tédio e da poeira na opinião de alguns de seus habitantes contrastava com os números do progresso, materializados nas ações empreendedoras dos governantes e registradas repetidas vezes pela imprensa (curiosamente, essa mesma imprensa que demarcava características pouco civilizadas da cidade). Nesse cenário novo (dada a juventude da própria capital), conflituoso e vertiginoso, onde a designação de cidade moderna (palavra mágica que promete um mundo mágico, nos dizeres de Sevcenko, 1993) e sua legitimação eram fatores de reconhecimento e propagação urgentes, os esportes e as demais manifestações de divertimento - tais como o cinema, o teatro, os bailes, dentre outros - constituíram-se como uma possibilidade de se afastar os caracteres do atraso e do provincianismo; um dos caminhos para que Belo Horizonte pudesse se consolidar, efetivamente, "como a metrópole de alguma coisa" (BELLO HORIZONTE, 1933, p.6). 


\section{Considerações Finais}

O presente artigo objetivou problematizar a veiculação, pela imprensa periódica, da diversão e do esporte como uma das formas de se possibilitar o alcance do progresso e da modernidade na cidade de Belo Horizonte. Junto a outros indicativos de evolução do município, amparados especialmente por marcadores numéricos que atestavam o crescimento urbano almejado, manifestações esportivas e de divertimento, bem como lugares construídos especialmente para ambas as finalidades, foram divulgados como importantes ações na promoção de uma ideia de cidade próspera e moderna.

Pode-se dizer que em Belo Horizonte, cidade nascida com o regime republicano e idealizada para representar um símbolo supremo desta forma de governo, os divertimentos e os esportes caminharam junto a outras estratégias de desenvolvimento da cidade e seu incentivo e veiculação se direcionavam, sobremaneira, à proposição de novos costumes aos moradores. $\mathrm{O}$ incitamento ao gosto e à admiração por manifestações desta natureza estavam no cerne das ambiguidades contidas no desejo da capital mineira de ser uma metrópole moderna, ainda que esta modernidade tenha sido absolutamente relativa, materializada por suas próprias condições locais.

\section{REFERÊNCIAS}

O ANNIVERSARIO da capital. Diário da Tarde. Belo Horizonte, 12 de dez. 1910 n.192, p.3.

O ANIVERSÁRIO de Belo Horizonte. Belo Horizonte, agost. 1944, n.166, p. 52-55.

ARRUDA, Rogério Pereira de. Belo Horizonte e La Plata: cidades-capitais da modernidade latino-americana no final do século XIX. Revista de História Comparada. Rio de Janeiro, v. 6-1, 2012, p.85-123.

BAHÍA, Denise Marques. Casa do baile 66: uma ilha de história. Prefeitura de Belo Horizonte, Fundação Municipal de Cultura. Belo Horizonte: Artes Gráficas Formato, 2008. 
BARRETO, Abílio. Belo Horizonte e sua história. Leitura. Belo Horizonte. n.8, p. 1922, 1940-1941.

BARRETO, Abílio. O vertiginoso evoluir de Belo Horizonte. Belo Horizonte, Belo Horizonte. Agos. 1944, n.166, p.42.

BELO HORIZONTE. Alterosa. Belo Horizonte, agosto, n.76, p.134, 1946.

BELO HORIZONTE: cidade das artes. Minas Tenis. Belo Horizonte. Jan.1944, n.2, p.10.

BELO HORIZONTE espelha a intensidade. Belo Horizonte, Belo Horizonte.... 22 de jan.1942, n.22, p.74-75.

BELO HORIZONTE, um convite ao turismo. Belo Horizonte. Belo Horizonte, agost. 1944, n.166, p.58-59.

BELLO HORIZONTE. Belo Horizonte. 28 de out. 1933, n.10, p.6.

BELLO HORIZONTE: symbolo de trabalho, tenacidade e optimismo. Bello Horizonte. Belo Horizonte, agost. 1940, n.119, p.20-21.

BERMAN, Marshall. Tudo que é sólido desmancha no ar. São Paulo: Companhia das Letras, 2007.

BIMBO. Chronica cinematográfica: Bilhete para Walt Disney. Bello Horizonte. Belo Horizonte, 16 de nov. 1933, n.12, p.3.

BOMENY, Helena. Guardiães da razão. Rio de Janeiro: editora UFRJ, 1994.

BOURDIEU, Pierre. A distinção. Crítica social do julgamento. São Paulo: Edusp; Porto Alegre, RS: Zouk, 2007.

BRANDÃO, Carlos Antônio Leite. A "modernidade fraca" das "esquinas" de Belo Horizonte e Cyro dos Anjos. In: SOUZA, Eneida Maria de; MARQUES, Reinaldo (Org.). Modernidades alternativas na América Latina. Belo Horizonte: Editora UFMG, 2009, p.100-115.

BRESSER-PEREIRA, Luiz Carlos. Getúlio Vargas: o estadista, a nação e a democracia. In: BASTOS, Pedro Paulo Zaluth; FONSECA, Pedro Cezar Dutra (Org.). A era Vargas: desenvolvimentismo, economia e sociedade. São Paulo: Editora Unesp, 2012, pp. 93-120.

BRILHANTES solenidades... Estado de Minas. Belo Horizonte, 15 de mai.1943, p.3.

CARVALHO, José Murilo de. Ouro, terra e ferro: vozes de Minas. In: GOMES, Ângela de Castro. Minas e os fundamentos do Brasil moderno. Belo Horizonte: Editora UFMG, 2005, p. 55-78. 
CARVALHO, Marcus Vinícius Corrêa. Moderno, modernidade, modernização: polissemias e pregnâncias. In: Moderno, modernidade, modernização: a educação nos projetos de Brasil - séculos XIX e XX. GIL, Natália; da CRUZ e ZICA, Matheus; FARIA FILHO, Luciano (Orgs.). Belo Horizonte: Mazza Edições, 2012, p. 13-34.

CHARAUDEAU, Patrick. Discurso Político. São Paulo: Contexto, 2006.

CIDADE das montanhas. Bello Horizonte. Belo Horizonte, dez.1936, n.75, p.39.

CIDADE do tédio. Bello Horizonte. Belo Horizonte, 09 de nov.1933, n.11, p.29.

CINQUENTENÁRIO. Alterosa. Belo Horizonte, dez, 1947, n. 188, p.1.

COMEMOROU Belo Horizonte seu $48^{\circ}$ aniversário. Belo Horizonte, jan.1945, n.179, p.87.

DIAS, Juventino. Os homens que fizeram o cinema Brasil... Bello Horizonte. Belo Horizonte, 16 de nov. 1933, n.12, p.6.

DOM Ruy. Avenida. Bello Horizonte. Belo Horizonte, dez. 1936, n.75, p.13.

12 de dezembro, a data anniversaria da cidade. Bello Horizonte. Belo Horizonte, jan.1939, n.111, p.21.

DUAS cartas da história de Belo Horizonte. Leitura. Belo Horizonte, dez-fev. 1940, n.8, p.11.

ENTREGUES á população as novas e modernas instalações do Cine Brasil. Alterosa. Belo Horizonte, agost.1943, n.40, p.90.

ESPÍRITO investigador... BELLO HORIZONTE. Belo Horizonte, 16 de nov.1933, n.12, p.1.

HOBSBAWM, Eric. A invenção das tradições. Rio de Janeiro: Paz e Terra, 1997.

JULIÃO, Letícia. Belo Horizonte: itinerários da cidade moderna (1891-1920). In: DUTRA, Eliana de Freitas (Org.) BH: Horizontes históricos. Belo Horizonte: C/ARTE, 1996, p. 49-119.

JUSCELINO KUBITSCHEK, o animador da cidade. Minas Tenis. Belo Horizonte, Jan.1944, n.2, p.12.

MELO, Victor Andrade de. Apresentação. Esporte, cidade e modernidade: a proposta desse livro. In: (Org.). Os sports e as cidades brasileiras: transição dos séculos XIX e XX. Rio de Janeiro: Apicuri, 2010, p. 05-18.

MELLO, Ciro Flávio Bandeira de Mello. A noiva do trabalho: uma capital para a república. In: DUTRA, Eliana de Freitas (Org.) BH: Horizontes históricos. Belo Horizonte: C/ARTE, 1996, p. 11-47. 
A METROPOLE da gente mineira. Belo Horizonte, Belo Horizonte, agosto,1946, n.184, p.20.

MIRANDA; CASTRO. A capital exige um teatro popular. Alterosa. Belo Horizonte, jul.1943, n.39, p.37.

A MULHER mineira nos esportes. Alterosa. Belo Horizonte, jan., n.22, p.34, 1942.

OS PLASMADORES da belleza architetonica da cidade-vergel. Bello Horizonte. Belo Horizonte, jan. 1937, n.77, p.32.

PRAÇA Sete. Belo Horizonte. Belo Horizonte, jun.1947, n.185, p.1.

REGISTRO. Belo Horizonte. Belo Horizonte, jan,1943, n.148, p.3.

RODRIGUES, Marilita Aparecida Arantes. Constituição do sentido moderno de esporte: pelas trilhas históricas do Minas Tênis Clube. Dissertação (Mestrado). Escola de Educação Física, Fisioterapia e Terapia Ocupacional, UFMG, 1996, 325p.

SEVCENKO, Nicolau. Transformações da linguagem e advento da cultura modernista no Brasil. Estudos Históricos, Rio de Janeiro, vol.6, n.11, 1993, p. 78-88.

Futebol, metrópole e desatinos. Revista USP. São Paulo, n.22, 1994, p.30-37.

SOUZA NETO, Georgino Jorge de.; SOUTTO MAYOR, Sarah Teixeira. Entusiasmo, estranhamento e resistência: discursos da imprensa belo-horizontina sobre o jogo de shoots (1904). Revista Acervo. Rio de Janeiro. v. 27, n.2. 2014, p.161-171.

TURISMO. Minas Tenis. Belo Horizonte, jan. 1944, n.2, p.30-31.

UMA das mais vastas realizações da energia mineira. Alterosa. Belo Horizonte, agost.1939, p.52-53.

\section{Endereço dos Autores:}

Sarah Teixeira Soutto Mayor

Rua Paulo Piedade Campos, 300, apto 102. Estoril

Belo Horizonte - MG - 30.494-225

Endereço Eletrônico: sarahtsouttomayor@hotmail.com

Sílvio Ricardo da Silva

Departamento de Educação Física

Escola de Educação Física, Fisioterapia e Terapia Ocupacional

Universidade Federal de Minas Gerais.

Av. Pres. Antônio Carlos, 6627, Campus Pampulha

Belo Horizonte - MG - 31.270-901

Endereço Eletrônico: prof.srs@gmail.com 